\title{
RESENHAS
}

\section{THE CONSEQUENCES OF DECISION-MAKING}

Nils Brunsson

Oxford: Oxford University Press, 2007, 166p.

Não raro os educadores padecem de ingenuidade política e científica quando se trata das contradições entre planos e programas no que se refere ao provimento e execução de recursos e à sua concretização na realidade. Vivese atualmente a chamada era organizacional, em que proliferam cada vez mais as organizações de naturezas distintas: estatais, privadas, educativas, filantrópicas etc. Elas passaram a fazer parte da vida do homem, tornando-se o meio em que ele despende a maior parte de seu tempo e constituindo recurso imprescindível à satisfação de parte de suas necessidades. Verifica-se nesta obra que a organização não é um ator singular, mas um conjunto em parte descoordenado de indivíduos e grupos ou departamentos com diferentes interesses e costumes e, por isso, envolvido em constante competição ou conflito. Por essas e outras razões, as organizações têm sido objeto de estudo, em seus aspectos internos e externos, nas mais diferentes áreas do conhecimento, como Psicologia, Sociologia, Antropologia, Administração, Educação, Direito etc. Pesquisadores têm-se dedicado a estudar aspectos como estruturação, funcionamento, conflitos, ações, funções, administração e processos decisórios.

Nils Brunsson, autor da obra em foco, é um desses pesquisadores, que se destaca pela audácia com que discorre sobre uma temática que, num primeiro momento, parece ir de encontro aos valores esperados pelo leitor: a da hipocrisia organizacional. Professor da Escola de Economia de Estocolmo, em que detém a
Cátedra Cidade de Estocolmo, em administração dedicou-se a pesquisar e escrever sobre as organizações, tanto no que se refere à tomada de decisões, quanto às reformas administrativas. Nesta obra são reunidos e revistos textos publicados nos últimos vinte anos, sobre os processos decisórios tanto em organizações públicas quanto privadas. $\bigcirc$ autor adota a perspectiva de "fora" da instituição para questionar a racionalidade dos processos decisórios, argumentando ser este um aspecto importante para compreender outras consequências desses processos para além das escolhas, como, por exemplo, o mobilizador da ação, que atribui responsabilidade e legitima a organização.

Para apresentação de suas ideias, Brunsson destaca uma característica peculiar da cultura ocidental, em que se considera ou se pressupõe que os atores de uma organização estão unidos entre si, são coerentes entre si, coordenados e que as organizações são capazes de falar, decidir e agir por meio de pessoas que controlam as suas ações. As inconsistências entre os atores, no entanto, parecem muito mais frequentes e problemáticas, sugerindo que a pressuposição da cultura ocidental não se veri ca na realidade.

A obra está organizada em oito capítulos. Nos seis primeiros, o autor apresenta ao leitor a "vida política" de uma organização, com base em aspectos relevantes, tais como: estrutura, liderança, interações, comportamentos, legitimação, reformas, controle, políticas, orçamentos, responsabilidades e decisões, isto é, o dia a dia da organização, em que seus gestores buscam legitimá-las e, ainda, dar conta de demandas contraditórias, de modo a agradar a gregos e troianos. Nesses capítulos, o autor prepara o leitor para refletir em profundidade, no capítulo seguinte, sobre uma realidade das 
organizações, que é a hipocrisia organizacional. No sétimo capítulo, intitulado "Hipocrisia organizada", ideia central do livro, Brunsson apresenta de nições bem mais amplas do termo que as dos dicionários, uma vez que a hipocrisia organizacional de que trata o autor envolve falas, declarações, decisões e ações relacionadas a coisas que se encontram fora do mundo moral. Isso significa que o conceito de hipocrisia não tem conotação pejorativa ou condenatória. Em vez de um juízo de valor, corresponde a um juízo de realidade sobre o comportamento das organizações. Portanto ele considera que não há necessariamente uma correspondência entre o que é dito e o que é feito numa organização; em vez disso, pode ser verdadeiro que várias pessoas acreditem que aquilo que é dito seja feito, outras pensam que aquilo que é decidido é certo; enquanto outras supõem que aquilo que é supostamente feito é verdadeiro. Para tornar mais claro ao leitor o que considera como hipocrisia organizacional, o autor se refere ao exemplo do cumprimento dos orçamentos públicos, que podem atender a vários desejos como se fossem leis, mas cuja execução pode eleger outras prioridades que não refletem a lei. gestor pode repassar primeiro as verbas para aquilo que considerou real prioridade, enquanto o restante ca por ser executado. Assim, a hipocrisia organizacional é justi cada pela necessidade de sobrevivência e funcionamento da organização e decorre essencialmente da sua demanda de legitimidade social. Por isso, no oitavo e último capítulo, a partir da associação entre ideias e ações, a hipocrisia organizacional é apresentada como ferramenta de controle alternativo para os gestores.

Por meio desta obra, Nils Brunsson evidencia que as decisões estão em frequente contradição com as ações. Conduz, portanto, o leitor a perceber a importância dessa hipocrisia como condição essencial à organização e, então, a quebrar ideias preconcebidas. $\bigcirc$ autor dá vários exemplos, a fim de que o leitor perceba que a hipocrisia organizacional funciona como uma forma de "desatar o nó" existente nos conflitos intergrupais, conferindo à organização flexibilidade para solucionar seus conflitos. Assim, verifica-se que, ao contrário do que se pensa, essa ambiguidade é uma solução, em vez de um problema. Justifica Brunsson que a hipocrisia organizacional acontece devido às pressões, às normas e às exigências que ocorrem em seu interior, muitas vezes inconsistentes e contraditórias, tornando-se, pois, parte da cultura das organizações. Em outras palavras, a organização apresenta os projetos ao seu entorno, documentando as estratégias e objetivos previstos, entretanto, as ações efetivadas não correspondem necessariamente às ações anunciadas pelos intervenientes como organização política.

A hipocrisia organizacional serve como um manto para esconder determinados fatos e buscar agradar a diferentes grupos sociais, inclusive o chamado público. Ela consiste na maneira pela qual os indivíduos e organizações manejam e gerem pelo menos grande parte dos seus conflitos, procurando satisfazer às demandas em que discursos e decisões atendem a certos grupos, enquanto outros grupos são atendidos pelas ações. Isso é possível porque poucas são as pessoas que acompanham a execução de um projeto ou programa (aplicação de recursos, ações, decisões). Essa camuflagem de discursos e ações acontece porque os executores das ações tendem a não ser os grandes decisores que buscam mudar a organização.

Para tornar claro como a hipocrisia organizacional é um processo "natural" na organização diante dos problemas que nela surgem, o autor descreve conceitos importantes como decisão, escolha, ação, discurso, que ocorrem durante o processo de legitimação da organização e que, por sua vez, tomam proporções diferentes das regras consagradas para escapar 
de grandes conflitos e satisfazer aos seus apoiadores e ao público.

O autor trata ainda de conceitos como racionalidade e irracionalidade e chama a atenção para o livre-arbítrio do indivíduo, capaz de tomar decisões racionais, coerentes, compatíveis e intencionais. No entanto, essas decisões nem sempre ocorrem. Dessa forma, as organizações estão longe de ser totalmente racionais. $\mathrm{Na}$ verdade, as decisões que nelas se tomam são frequentemente irracionais, levando em conta as preferências presentes. Não há necessariamente correspondência entre decisão (que pode ser pública) e ação (menos pública). Pode haver decisão isolada da ação, assim como não existem relações necessárias entre as causas e as consequências. Isto é, as decisões podem ser separadas das ações. Contudo, os processos entre ações verdadeiramente efetivadas e a tomada de decisões nas organizações não são acompanhados minuciosamente por grande parte das pessoas dentro e fora da organização, o que determina que a hipocrisia organizacional seja e caz. Além disso, a maioria dos decisores não tem capacidade de processar complexas informações, nem está xada na racionalidade das escolhas. Em muitos casos, as escolhas são feitas aleatoriamente e no calor dos acontecimentos. Contudo, o autor também considera que nem sempre as decisões estão conectadas às escolhas. Estas são causas das ações, o que implica aparentemente escolhas. Dessa maneira, vários fatores entram em ação quando as organizações decidem. Então, pode-se decidir para o público de um modo, por assim dizer na boca do palco, mas a ação pode ser executada por outras pessoas, nos bastidores, de maneira diferente daquela decidida. As decisões são vistas como um tipo especial de fala que indica um desejo de agir e escolher uma ação. Pela teoria tradicional, a decisão é tomada para ser um indicativo da correspondente ação que ocorrerá no futuro, mas, de maneira irracional, pode haver o contrário, isto é, em busca de atender a vários grupos e legitimar as suas decisões, a organização pode usar de hipocrisia, falando de uma maneira e agindo de outra. Nesse caso, ou em todos os outros abordados pela obra, a hipocrisia organizacional deve ser vista não como juízo de valor sobre aquilo que deveria ser nas organizações. A hipocrisia nesse caso não é um defeito, nem uma virtude, ela é uma realidade, um processo utilizado pelas organizações para se protegerem, mantendo aliança com diferentes grupos e legitimidade em face deles. Não é, portanto, um problema, mas em muitas situações pode ser uma solução. Como a organização precisa satisfazer a muitos anseios conflitantes e a problemas angustiantes que parecem em determinado momento insolúveis, a hipocrisia organizacional cobre com um véu a relação entre declarações, ideias, valores e ações.

A probabilidade de uso da hipocrisia organizacional aumenta à medida que alternativas se revelam pouco úteis, como as soluções de compromisso, em que demandas dos diversos grupos são parcialmente atendidas, porém nenhuma o é plenamente. As tensões entre ideologia e prática, além da di culdade de resolver determinados problemas, são também fatores de uso dessa hipocrisia. Considera Brunsson que não há garantia de que as ideias que têm maior repercussão possam efetivamente ser praticadas.

Essa condição de hipocrisia organizacional estudada por Brunsson corresponde a uma dimensão antiga na cultura ocidental. Anísio Teixeira', por exemplo, apresenta como fator existente desde a descoberta da América, quando os europeus impunham aos colonizados

I. TEIXEIRA, A. S. Valores proclamados e valores reais nas instituições escolares brasileiras. Revista Brasileira de Estudos Pedagógicos, Rio de Janeiro, v.37, n.86, p.59-79, abr./jun. 1962 (disponível em: http://www.bvanisioteixeira.ufba.br; acesso em: 3 I ago. 2009). 
leis que não condiziam com suas realidades, portanto, ineficazes para aquele público. As leis fixadas pelos europeus se traduziam em padrões elevados e estranhos à cultura local, contrários às condições sociais, excluindo, assim, os menos favorecidos das oportunidades educacionais e, dessa forma, impedindo a expansão educacional. Portanto, se pode verificar, em Teixeira (1962), que essa duplicidade entre os valores proclamados e reais faz parte da realidade educacional brasileira desde a era colonial, pois já ocorria desde então o hiato entre o que se preconizava e o que se praticava efetivamente nas escolas.

Passados alguns anos, Benno Sander ${ }^{2}$ também tratou da contradição entre teoria e prática ao abordar o formalismo educacional brasileiro, referindo-se às discrepâncias entre a norma prescrita e a conduta real. Esse fato decorre da condição transicional chamada prismática, que de ne heuristicamente as sociedades periféricas, semidesenvolvidas, em processo de desenvolvimento, emergentes ou transicionais, con rmando de certo modo o que propôs Teixeira (1962) ao discorrer sobre a duplicidade da aventura colonizadora da América. Sander (1977) argumenta então que a instituição escolar, como está instituída, isto é, presa a decretos, pareceres e outras normas estabelecidas pelos ministérios, secretarias e conselhos, algumas vezes inconsistentes com as necessidades de sua clientela, é levada à prática da hipocrisia organizacional em meio a valores contraditórios para satisfazer o seu público. Os dois autores brasileiros citados oferecem pistas de que a teoria da hipocrisia organizacional de Brunsson teria fundamento.

Em um primeiro momento, parece uma obra eticamente duvidosa, porque levaria o

2. SANDER, B. Educação brasileira: valores formais e valores reais. São Paulo: Pioneira, 1977. leitor a adotar uma postura cínica diante de valores democraticamente consensuados. No entanto, para o profissional da educação, ela permite "entender" o que acontece na execução e no desfecho de projetos e programas na organização escolar.

Adriana Lira

Mestranda em Educação da Universidade Católica de Brasília. Pesquisadora e voluntária da Cátedra Unesco de Juventude, Educação e Sociedade da Universidade Católica de Brasília adrianalina@ucb.br

\section{LETRAS, OFÍCIOS E BONS COSTUMES: CIVILIDADE, ORDEM E SOCIABILIDADE NA AMÉRICA PORTUGUESA}

Thaís Nivia de Lima e Fonseca

Belo Horizonte: Autêntica, 2009, I76 p.

Thaís Nivia de Lima e Fonseca é graduada em História e mestre em Educação pela Universidade Federal de Minas Gerais - UFMG - e doutora em História Social pela Universidade de São Paulo. Fez estudos de pós-doutoramento na Universidade Federal Fluminense e na Universidade de Lisboa. É professora adjunta da Faculdade de Educação da UFMG, onde atua na linha de pesquisa História da Educação. Coordena projeto de pesquisa sobre os processos e as práticas educativas na capitania de Minas Gerais no Grupo de Estudos e Pesquisas em História da Educação - Gephe - da Faculdade de Educação - FAE - da UFMG. É também autora de História \& ensino de história, e organizadora de Inaugurando a história e Construindo a nação: discursos e imagens no ensino de história e História e historiografia da educação no Brasil.

O livro em apreço traz uma análise de estratégias e práticas educativas que fizeram e fazem ainda parte da formação cultural brasileira, fruto de pesquisa focalizada na educação no período colonial do Brasil, que considera a 
diversidade e peculiaridade da sociedade de então. Resultado do exame da documentação disponível no Brasil e em Portugal abordada sob o ponto de vista de uma concepção mais ampla da educação, trata tanto das ações de natureza escolar quanto das práticas educativas não escolares, construídas no cotidiano do período colonial, ainda pouco explorado pelos historiadores da educação.

$\mathrm{Na}$ introdução, "A população 'deseducada' da América portuguesa", Fonseca faz um balanço da produção referente à historiografia da educação que trata especificamente do Brasil colonial, apontando a escassez de trabalhos e de obras inteiras dedicadas à educação no período. Entre as existentes, destaca sua concentração no exame da atuação educacional da Companhia de Jesus e das reformas promovidas pela administração do Marquês de Pombal, na segunda metade do século XVIII. A maioria, centrada nas ações do Estado e da Igreja, deixa em segundo plano outras dimensões dos processos educativos na América portuguesa, as quais serão apontadas ao longo do livro. A autora faz ainda uma breve revisão da literatura e do debate historiográfico sobre o tema e discute desde as visões mais tradicionais até os estudos recentes realizados no Brasil e em Portugal, apontando possíveis falhas, méritos e avanços dessa produção, e levantando questões relevantes para o avanço do conhecimento. São explicitados os processos de pesquisa, as fontes e as perspectivas teóricas adotadas, que trabalham com a ideia de práticas educativas, tributária do conceito de práticas culturais, desenvolvido por historiadores e sociólogos, como Michel de Certeau, Pierre Bourdieu e Roger Chartier, e utilizam também outros conceitos e ideias desses e outros autores.

Questões referentes a diversas capitanias aparecem nos dois primeiros capítulos, por meio da documentação utilizada para tratar seja dos discursos, seja das práticas em rela- ção à civilização e à educação dos povos. Em decorrência do foco da pesquisa na Capitania de Minas Gerais, há ênfase na análise das manifestações das diversas formas de educação nessa região. É o que caracteriza as duas últimas partes do capítulo 2 e todo o capítulo 3.

No capítulo I, "Civilização e educação nos setecentos", na seção "A civilidade moderna e a formação do 'novo' súdito", são analisados o pensamento da intelectualidade da idade moderna e sua produção nos séculos XVII e $\mathrm{XVIII}$, bem como a perspectiva universalista que adquirem, ampliada com o iluminismo. Segundo a autora, duas dimensões da educação - promover a união dos indivíduos em sociedade e disseminar valores e normas de comportamento - integravam as funções atribuídas à ação civilizadora apregoada por esse pensamento. Na perspectiva de uma educação civilizadora, destaque é dado à formação moral, entendida em suas dimensões civil e religiosa, não necessariamente separadas uma da outra. É feita uma revisão do pensamento dos principais intelectuais da época, pensamento esse que influenciou o modelo de formação para a civilidade imposto pelo império português. É também registrado o processo de laicização em curso na idade moderna e acentuado no século XVIII, bem como o papel cada vez mais central da educação nas preocupações quanto à organização da vida social, evidente, por exemplo, nas reformas pombalinas marcadas, entre outros atos, pela expulsão dos jesuítas da América portuguesa.

Na seção seguinte do capítulo I, "Discurso civilizador e práticas educativas na América portuguesa", a autora faz uso da análise do discurso presente na farta documentação produzida pelos europeus durante o período colonial, principalmente nos textos produzidos por diversas autoridades portuguesas, em que se evidencia a preocupação com o estado de "descontrole" e de "falta de civilidade" dos 
domínios americanos, especialmente da região das minas. Assinala que o sentido atribuído à ideia da educação para a população não era evidentemente próximo do que entendemos hoje como um sistema de educação pública, que apenas principiava sua trajetória, nos últimos anos do século XVIII, na Europa. Nesses documentos, a educação, fosse qual fosse sua natureza, surgia como solução possível. É também apontada a constante presença, no discurso das autoridades, da relação entre a barbárie da população, o estado de constante ameaça à ordem e a necessidade de se educar e civilizar os povos, para que se tornassem súditos obedientes às reais ordens. São apresentados, ainda, os modos pelos quais eram tratadas - em termos de educação - as classes mais baixas, os escravos e libertos, os órfãos e as demais crianças, sempre considerando o gênero e a posição social. É examinada ainda a educação pela ocupação e pelo exemplo, e a educação para o trabalho nas minas gerais, ligada diretamente aos problemas da produção, mineral e agrícola; são considerados ainda os ofícios que surgiam em uma sociedade com grande urbanização: alfaiates, artesãos, músicos etc.

No capítulo 2, "Civilizar e educar os súditos na América portuguesa: reformas, impactos, cotidiano", na seção "Historiografia das reformas pombalinas da educação", Fonseca aponta a possibilidade de várias abordagens dessas reformas, em vista dos diferentes desdobramentos que tiveram. No tocante à educação, a autora apresenta a visão de conjunto que as coloca no movimento de oposição do Estado à Companhia de Jesus, não deixando dúvidas quanto ao impacto provocado por elas nas regiões em que a educação era monopólio da ordem religiosa. Todavia levanta diversas questões acerca da análise do impacto das reformas, como a necessidade de estudá-lo em regiões nas quais os jesuítas não atuavam ou não havia nenhuma instituição educacional ligada à ordem religiosa, como era o caso da Capitania de Minas Gerais, entre outras. Uma apreciação do debate historiográfico acerca dos impactos das reformas pombalinas, desde o final século XIX e início do $X X$, passa pelas perspectivas de Fernando de Azevedo, apontando a polarização do debate entre os autores portugueses que viam o Marquês de Pombal como um expoente do pensamento progressista português e os que consideravam seu governo despótico e destruidor das tradições. São evidenciados avanços na recente historiografia portuguesa que trata da educação e a minoritária produção da historiografia da educação brasileira sobre o período colonial, com exemplos de abordagens verticalizadas sobre alguns casos específicos de capitanias que sofreram significativo impacto das reformas. Certo consenso entre os trabalhos sobre educação no Brasil colonial no âmbito das reformas pombalinas é demonstrado no que diz respeito às formas de arrecadação do subsídio literário e aos desvios e fraudes na contabilidade. Também é apontado como situação comum a diferentes regiões do Império português, o maior ou menor jogo de influências quando havia a presença de bispados.

Na seção "As reformas e seus impactos: aulas régias e professores na América portuguesa", Fonseca mostra as dificuldades da administração dos estudos na colônia, algumas comuns às diversas capitanias, outras mais específicas conforme as condições locais, desde a primeira etapa das reformas, como decorrência da expulsão dos jesuítas, bem como a sequência de instrumentos legais impostos a partir de 1759 Deixando claras as desconfianças em relação à docência dos religiosos, mesmo dos não jesuítas, principalmente nas capitanias em que as ordens possuíam conventos e colégios, a autora associa essas atitudes ao "espírito" formulador das reformas, que visava colocar sob o controle do Estado várias atividades importantes da sociedade portuguesa da época, entre elas 
a educação, responsável pela formação dos melhores súditos. Com o início da segunda fase das reformas, mediante as leis de novembro de 1772 que reformaram os estudos menores e criaram o subsídio literário, intensificou-se o processo de escolarização pela criação de maior número de aulas régias, realização dos exames para provimento de cadeiras, pelo estabelecimento mais nítido dos valores dos ordenados dos professores, e de algumas normas gerais de administração e controle do trabalho docente. É defendida a tese de que as reformas pombalinas da educação propiciaram relativa expansão da escolarização, se considerada sua concentração institucional anterior, nas mãos da Companhia de Jesus e de algumas outras ordens religiosas, assim como se advoga que a criação das aulas régias e de todo o aparato relacionado ajudou a iniciar o processo de formalização do ensino e da profissão docente na América portuguesa.

Na seção "Professores régios e os modelos de bons costumes", a autora lança luz sobre esses professores na Capitania de Minas Gerais, sua participação na vida social e cultural, suas diferentes origens e trajetórias pessoais, reconstituindo algumas delas a $\mathrm{m}$ de esclarecer questões sobre o funcionamento da estrutura do ensino régio na América portuguesa. Para tanto, faz uso de uma perspectiva micro-histórica. Trata de temas diversos do universo dos professores régios mencionando alguns como exemplos, aponta as perspectivas de civilização oriundas do iluminismo português, as qualidades esperadas dos mestres, que incluíam aspectos físicos e médicos, além de morais (como ser casado), e os exames de admissão a que eram submetidos. Refere-se ao tipo de educação destinado às elites - cuja essência eram a moral, o direito natural e o direito civil; a cuidados com os costumes dos alunos, incluindo a prática da religião, a fim de formar, além de um bom cidadão, um bom cristão, e menciona casos de denúncias contra professores feitas pelos pais às autoridades civis e religiosas da inquisição no Tribunal do Santo Ofício.

No capítulo 3, "Pobres ou abastados, os súditos se instruem e se educam na Capitania de Minas Gerais", Fonseca demonstra, na seção "Civilizar e educar os órfãos e os pobres", como ocorre a educação das camadas mais baixas da população mineira, associada à difusão da doutrina cristã e à formação profissional como meios de controle e realizada predominantemente em instituições de natureza caritativa, ligadas a ordens religiosas ou particulares. Desse modo, o ensino das primeiras letras visava fundamentalmente facilitar o aprendizado da doutrina, sem implicar a criação de possibilidades de ascensão social pela educação. De acordo com a autora, se em muitas capitanias foram abertos estabelecimentos que podiam abrigar órfãos e expostos pobres, dar-lhes sustento e educação, nas Minas Gerais sua existência foi tardia e menos vinculada diretamente à Igreja. Isso porque a presença das ordens religiosas foi proibida ali no início do século XVIII, e a assistência associada à instrução limitou-se à dimensão leiga. $\bigcirc$ espaço religioso foi ocupado pelas associações leigas - irmandades e ordens terceiras - que proporcionavam certa inserção social e proteção, principalmente aos seguimentos menos favorecidos da população, sendo que suas ações possuem mais um caráter assistencial do que educacional propriamente dito. Fonseca aponta ainda outras instituições voltadas para $\mathrm{o}$ atendimento às necessidades sociais e religiosas da Capitania de Minas Gerais, como dois recolhimentos femininos, importantes para a educação das mulheres abastadas ou pobres, e o Seminário de Mariana, interferência mais direta da Igreja na educação, criado em 1750 pelo bispado local. A autora lembra que, para os pobres, a educação voltava-se prioritariamente para o aprendizado de ofícios mecânicos, embora eventualmente eles também fossem 
levados a aprender a ler, escrever e contar. Foi relevante ainda a atuação de professores particulares, principalmente de primeiras letras, mesmo depois da instituição das aulas régias, bem como dos mestres de ofícios mecânicos.

Na seção "Letras, ofícios e bons costumes longe da educação estatal", Fonseca concentra a análise na Comarca do Rio das Velhas, mais particularmente na Vila de Sabará e seu termo, sobre a qual vem sendo realizada a pesquisa mais verticalizada acerca da educação fora do âmbito do Estado. Aqui é defendida a tese de que, muito antes das reformas pombalinas da educação e da criação das aulas régias, a população da Capitania de Minas Gerais já construía importantes relações com as práticas educativas que poderiam quer resultar no aprendizado da leitura e da escrita ou gramática, quer no de ofícios mecânicos, todos associados, de alguma forma, à doutrina cristã, por meio dos mestres particulares. São destacados aspectos da educação de meninos e meninas e as funções pedagógicas das irmandades e ordens terceiras.

A obra fornece subsídios importantes ao campo da História da Educação brasileira. Oferece contribuição no tocante à educação em diversas regiões da América portuguesa, antes e depois das reformas pombalinas e, principalmente, na Capitania de Minas Gerais, caso muito particular, haja vista leis específicas impostas à região para o maior controle do destino de suas riquezas minerais. Entre outras ações, essas leis proibiam a instalação nessa capitania de ordens religiosas responsáveis pela educação, como o caso emblemático da Companhia de Jesus.

Aporte relevante é dado à esfera da educação desvinculada do Estado e da Igreja, com apontamentos sobre as práticas informais, de iniciativa privada, de indivíduos ou grupos organizados, como as irmandades e ordens terceiras leigas. Igualmente importante é o trato dado à educação não escolar, não necessariamente visando ao aprendizado de leitura, escrita e cálculos, mas voltada ao trabalho, à formação moral e religiosa, à civilização e controle social, muitas vezes de caráter assistencialista, baseados em princípios como a caridade, próprios do bom súdito cristão.

Uma observação deve porém ser feita, sobre a falta de apontamentos relativos à população indígena na obra, principalmente quando trata do caso de Minas Gerais. Essa omissão, diga-se de passagem, é comum à maioria dos trabalhos sobre o período e a região. Não obstante a participação dos indígenas na sociedade mineira era, desde o início da chegada de europeus e africanos à região, relevante a ponto de, mesmo em períodos posteriores à independência do Brasil, surgirem projetos de cunho estatal para a civilização e educação desses povos nas Minas Gerais, o que mereceria maior atenção por parte dos pesquisadores.

Finalmente, há de se considerar a obra uma referência valiosa, tanto pelas qualidades metodológicas do trabalho, quanto pelas contribuições ao conhecimento de um período histórico ainda carente de estudos concernentes à educação.

Ageu Quintino Mazilão Filho Graduado em História (licenciatura e bacharelado) e mestrando em Educação pela Universidade Federal de São João del-Rei-MG ageumazilao@yahoo.com.br 


\section{USP PARA TODOS? ESTUDANTES COM DESVANTAGENS SOCIOECONÔMICAS E EDUCACIONAIS E FRUIÇÃO DA UNIVERSIDADE PÚBLICA}

Wilson Mesquita de Almeida

São Paulo: Musa; Fapesp, 2009, 208p.

$\bigcirc$ estudo se propõe uma pesquisa sobre o uso do amplo potencial formativo disponível na Universidade de São Paulo - USP -, por estudantes com desvantagens socioeconômicas e educacionais. Interroga a fruição das oportunidades educacionais no nível superior por meio de três eixos investigativos: socialização em ambiente familiar; trajetória de ingresso; socialização universitária.

O enfoque atual do debate sobre a questão é maior quanto ao acesso ao ensino superior (ainda bem diminuto: $8 \%$ a $9 \%$ dos jovens na faixa de 18 a 24 anos de idade) do que quanto à permanência nele. Isso parece acontecer em razão do crescente interesse das camadas desprivilegiadas de ingressar nesse nível de ensino. Por sua vez, o avanço das universidades particulares sobre a classe $C$ é agressivo, como se pode constatar em recentes matérias jornalísticas' como assunto de capa. $\bigcirc$ trabalho pretende, na contramão da tendência de incorporação dos jovens de baixa renda pelo setor privado, discutir a permanência efetiva de alunos com as características mencionadas na universidade pública. $\bigcirc$ passo a frente da pesquisa consiste em abordar, creio eu, o problema maior no ensino superior público: permanecer, usufruir e concluir o curso com boa formação.

I. TODESCHINI, M.; SALOMÃO, A. Um merguIho na nova classe média. Revista Época Negócios, n.33, capa/Economia, 5 nov. 2009; STANISCl, C., OLIVEIRA, E.; SALDANHA, P. A. Classe C com diploma. O Estado de S. Paulo, Cadernos Estadão Edu, p. I0-12, 24 nov. 2009.
Para tanto, a pesquisa estuda um grupo de alunos da USP, o que, ao mesmo tempo, torna o foco da investigação original e interessante: não se está falando de estudantes que terão o pior ensino entre os universitários, mas de um dos "biscoitos mais finos" que esse nível de ensino pode oferecer no país. É evidente que esse "biscoito fino" não está isento de problemas; no entanto, não é lá, certamente, que se imaginaria encontrar o estudante pobre, ou com "desvantagens socioeconômicas e educacionais", como as denomina Almeida.

O fato de ser a USP a universidade de origem do autor não empobrece seu ponto de vista: ao contrário, o enriquece porque, para construir a problemática, ele se vale da vivência do curso de graduação em uma das faculdades tidas como "irmãs pobres" 2 na universidade.

Para selecionar a amostra, o pesquisador recorreu ao questionário socioeconômico aplicado aos candidatos ao vestibular da USP de 2003, utilizando quesitos que considerou ter forte relação com o sucesso escolar. Foram levados em conta: a renda familiar dos alunos, a realização de estudos no período noturno, a frequência à escola pública, o fato de terem pai e mãe com baixa escolaridade. Com base nesses critérios, o per I dos sujeitos da amostra pode ser resumido da seguinte forma: escolarização fundamental e média realizada exclusivamente ou

2. Estamos nos referindo em especial aos cursos da Faculdade de Filosofia, Letras e Ciências Humanas - FFLCH -, a algumas licenciaturas (Física, Matemática, Ciências Exatas) e a outros cursos menos concorridos, como o de Contabilidade. Esse "desprestígio" não quer dizer, necessariamente, que os cursos não sejam bons ou não tenham boa infraestrutura. Alguns participantes da pesquisa elogiam, por exemplo, a estrutura impecável oferecida pela Faculdade de Economia, Administração e Contabilidade FEA - e pelo Instituto de Física - IF. O mesmo não ocorre com outros cursos da FFLCH, no dizer dos entrevistados. 
na maior parte em escola pública, ou em curso supletivo ou de madureza. Os que estudaram em escolas técnicas federais, sabidamente com qualidade comparável às melhores escolas particulares, foram excluídos. Além disso, o respondente deveria ter realizado a maior parte ou a totalidade dos estudos em período noturno; possuir pai e mãe com até o ensino médio incompleto e que não fossem empresários de qualquer porte ou pro ssionais liberais ${ }^{3}$; a renda familiar não deveria exceder a R\$3 mil. Um outro aspecto fundamental: os respondentes deviam também exercer alguma atividade remunerada no momento do ingresso e se sustentar durante o período do curso superior com sua própria remuneração, sem a colaboração dos pais.

Tais critérios são certamente rigorosos, porém, causa espanto que deles resulte, em todo o universo de ingressantes da USP em 2003, um subconjunto de apenas 39 indivíduos, dos quais 17 aceitaram participar da pesquisa ${ }^{4}$. Como procedimentos foram realizados dois grupos focais e entrevistas semiestruturadas. A discussão metodológica do autor, franca e madura, não hesitou em assinalar erros porventura cometidos e manifestou preocupação constante com a validade dos achados.

Dois reparos podem ser feitos. Um, que foge, na verdade, à competência do autor, é a predominância dos estudantes de ciências hu-

3. O questionário não é muito satisfatório em alternativas nesse sentido, mas a escolha do autor permitiu que fossem selecionados sujeitos com pais que se poderiam chamar "trabalhadores", aqueles que dependem da renda do trabalho para a sobrevivência.

4. Em 2003, foram convocados para matrícula em primeira chamada 9.910 candidatos, conforme - Questionário de avaliação socioeconômica, da Fuvest, 2003 (disponível em: http://www.fuvest. $\mathrm{br} / \mathrm{scr} / \mathrm{qase}$.asp? anofuv $=2003 \&$ fase $=3 \& \mathrm{carr}=\mathrm{T}$ OT\&quest $=0 \mid \&$ tipo $=3 \&$ grupo $=1$. Acesso em: 29 nov. 2009). manas na amostra. Esse aspecto, evidentemente, diz respeito ao menor prestígio e menor caráter competitivo dos cursos dessa área, aos quais os alunos de baixa renda "obrigatoriamente" recorrem, como se pode verificar na análise do seu processo de escolha. No entanto, é fato que, ao se aprofundar no cotidiano desses estudantes, a análise fica muito marcada pela experiência particular dos cursos de humanas da FFLCH. As diferenças são mostradas, é verdade, pelas experiências dos outros estudantes, ainda que em menor número.

outro reparo diz respeito à pouca importância dada aos condicionantes de gênero na questão do tempo. É conhecida a problemática do uso do tempo para as mulheres que, em razão de suas atribuições tradicionais em relação ao doméstico, incorrem em dupla jornada e, no caso das que estudam, em tripla. $\mathrm{Na}$ amostra, elas são minoria (seis mulheres e I I homens), todas solteiras e sem filhos. Entre os homens, apenas um tem filho, entretanto a média de idade das mulheres (só uma tem menos de 27 anos) é bem mais alta que a da parcela masculina (mais da metade do grupo, oito indivíduos, tem até 27 anos). Questões como essas poderiam ser problematizadas na perspectiva de gênero, assim como a composição sexual do grupo de desistentes.

O conjunto dos 17 estudantes compõese basicamente de filhos de migrantes nordestinos (pelo menos a metade deles), de população proveniente de cidades do interior do estado e da Grande São Paulo, ou ainda de alunos migrantes, eles mesmos (um vindo do Paraná e outro de Minas Gerais). São também trabalhadores-estudantes.

Outro aspecto de destaque é o papel das mães no incentivo à leitura. $\bigcirc$ estudo mostra que seus interlocutores são "pobres diferenciados", ou seja, entre aqueles que se encontram em situação socioeconômica e educacional desvantajosa, eles possuem algum tipo de van- 
tagem, o que os coloca, de alguma maneira, em condições de enfrentar o exame vestibular da Fuvest. Essas vantagens podem ser encontradas na trajetória social e familiar dos informantes, em diferentes combinações: incentivo aos estudos por parte dos pais, esses mesmos pouco escolarizados, ou de irmãos que conseguiram trilhar um caminho de relativo sucesso escolar e fornecem o necessário exemplo de possibilidade; escolas excepcionalmente boas, no sentido de que nem sempre são instituições de excelência, mas conseguem desenvolver capacidades mínimas entre os alunos.

Alguns dos sujeitos que compõem o estudo afirmam ter optado pela USP mais premidos pela necessidade do que pelo prestígio que o nome da universidade pudesse deixar em seus currículos. Nenhum deles ignorava, porém, a força e importância desse nome, revelando uma imagem quase "mítica" da universidade. Esse caráter mítico não impediu, no entanto, o pequeno grupo de entrar na universidade, mas certamente desviou alguns por um tempo, retardando, por exemplo, o momento de prestarem a prova vestibular. Isso leva a supor que milhares de alunos de escolas públicas são barrados, não na prova escrita, mas pelos obstáculos decorrentes da violência simbólica de que são alvo: a ideia recorrente de que a USP, ou qualquer universidade pública, ou, ainda, que o ensino universitário de qualidade, não é o lugar em que deveriam estar. É doloroso ler o relato de uma estudante sobre o que ouvia dos próprios professores: "alunos de escola pública, vocês, por exemplo, não vão entrar na USP". Outro estudante, levado em uma excursão da sua escola a conhecer a universidade, ouve de um dos monitores o comentário: "vocês de escola pública, é bastante difícil entrar aqui”. ○ comentário, seguido da correção de outra monitora, que afirma que é "difícil, mas não impossível", aponta para o subliminar "aqui não é o seu lugar".
Uma vez tomada a decisão de prestar o vestibular, é o momento de escolher o curso. O autor passa ao exame do processo de escoIha. Essa "escolha" com aspas significa que, em muitos casos, se trata de uma "não-escolha", ou de uma escolha restringida pelas condições materiais. Ao ultrapassarem as barreiras simbólicas que faziam da USP um "mito inatingível", os estudantes começam a apreender o "sentido do jogo"; mas, se a eles faltavam capital econômico e cultural, uma boa formação escolar e estímulos, a condição de desvantagem lhes proporcionava, enviesadamente, o desenvolvimento de estratégias do possível e lhes permitia encarar uma rotina extenuante de trabalho e estudo.

A tarefa de ser bem-sucedido no seletivo vestibular da USP, ainda que em carreiras menos concorridas, é lida através das lentes do "trabalhador-estudante". Aquele que estuda é, antes de tudo, um trabalhador, e por esse motivo carrega consigo os valores do trabalho, do esforço, da superação e da recompensa pelo mérito. Essa categoria explicativa que, à falta de melhor denominação, é chamada de "esforço descomunal" é que cria um "ethos do esforço e da responsabilidade". A discussão sobre cotas que emerge dos debates públicos apenas corrobora o perfil delineado pelo autor: majoritariamente contrários a elas, os participantes da pesquisa preferem apostar na "melhoria" da escola pública como forma de manutenção do critério meritório que reputam justo, sem, no entanto, ignorar a desigualdade de bases socioeconômicas inerente à disputa. Parecem, a um só tempo, incorporar os critérios puramente meritocráticos e, por meio da sua defesa, valorizar suas próprias trajetórias de conquista da vaga.

Uma vez conquistada a vaga, o cotidiano de estudo se afigura. As desigualdades entre os cursos no interior da universidade e, entre os alunos no interior de cada curso, são 
exploradas. Dimensões como a infraestrutura oferecida em termos de biblioteca e laboratórios; a sociabilidade: contato com colegas, ida a festas e outros eventos; a vivência em um ambiente diferenciado e privilegiado do ponto de vista intelectual; a dificuldade no manejo de línguas (seja o português, seja as demais línguas necessárias em determinados cursos, como inglês, francês e espanhol), apontam para outros e novos obstáculos a serem superados. Sublinhe-se o déficit quase incontornável em relação ao que os sujeitos chamam de "base", isto é, os conhecimentos fundamentais que deveriam ter adquirido nas etapas escolares anteriores e que agora fazem falta. $\bigcirc$ maior obstáculo é, contudo, a falta de tempo, até porque, se ela não impede, dificulta sobremaneira o acompanhamento do curso. O tempo, que para muitos é dinheiro, é escasso; faltam aos estudantes tanto um quanto outro.

As estratégias de acompanhamento do curso são inúmeras e frequentemente impróprias: avançar no tempo de sono, estendendo a jornada insone (alunos do período noturno que chegam em casa e continuam estudando ou que realizam os trabalhos das disciplinas nesse horário); deixar de ter "vida social", avançando no tempo de lazer, já exíguo, ou burlando o horário de trabalho para estudar, ter lazer, ou mesmo para tirar xerox dos textos de leitura às escondidas do chefe ou patrão. Esse malabarismo faz dos estudantes mestres em encontrar "brechas" no trabalho, no tempo, na vida, para prosseguir no curso universitário, o qual demonstram, muitas vezes, amar intensamente. São apaixonados - digo sem medo de parecer exagerada - pelo trabalho intelectual, e resistem às adversidades em razão disso. É por esse motivo que, de maneira tão adequada, Heloisa Martins afirma em orelha do livro: "É dessa elite que a universidade pública precisa: a que valoriza o conhecimento de qualidade e se esforça para alcançá-lo".
Para alguns estudantes, a aproximação com a "mítica" da USP os leva a enfrentarem a dura realidade de parcas instalações e recursos, conhecida entre os que frequentam os cursos mais "pobres" da universidade. Ainda distantes, mas em processo de preocupante aproximação, esses problemas fazem lembrá-los daquilo que gostariam de deixar no seu passado educacional: banheiros sujos, instalações e equipamentos precários das escolas públicas que frequentaram, a exemplo do documentário Pro dia nascer feliz, de João Jardim. Não se deve, a meu ver, descartar os efeitos desses aspectos no estímulo e na autoestima do estudante de qualquer nível. O contraste com unidades mais ricas, como a Faculdade de Economia e Administração e o Instituto de Física, constitui mais um indicador da desigualdade do interior da universidade.

Almeida faz por fim a sua discussão sobre a noção de "elite". Na verdade, aponta o uso impróprio do termo, no caso dos alunos da Universidade de São Paulo, chamada pela mídia e por alguns trabalhos acadêmicos pejorativamente de "elitista", no sentido de abrigar, primordialmente, as elites econômicas. $\mathrm{O}$ autor desmonta esses argumentos trazendo evidências de que a universidade pública, como espelho da sociedade, não é ocupada nem exclusivamente pela elite [econômica], nem pelos muito pobres, e sim, basicamente, pelos segmentos médios.

É verdade que há aqueles privilegiados,uma classe média "alta"

5. A discussão do autor sobre elites também tangencia uma discussão sobre "classe", apontando para a inadequação de alguns critérios classi catórios de natureza socioeconômica, como o "Critério de classi cação econômica Brasil". Segundo essa classificação, em números de 2006, a classe mais alta, a "Al", se caracterizaria a partir da renda média mensal de $\mathrm{R} \$ 7.793,00$. 
cionar melhores colégios ao filhos no período da educação básica. Entretanto, a instituição dá também lugar a uma classe média "remediada", que se priva de certos bens para dar educação aos filhos, e até a uma classe menos privilegiada, na figura dos seus membros, senão mais brilhantes, certamente, os mais persistentes. $\bigcirc$ pano de fundo dessa crítica, ainda que não explicite o autor, aponta para aqueles que se utilizam desses discursos para pleitear a privatização de universidades públicas, pois elas fariam o papel de um "Robin Hood às avessas", uma vez que tiram recursos dos impostos pagos por uma sociedade "pobre" para custear o ensino da camada "rica".

autor mostra que esses alunos, sem incentivo, conseguem chegar à universidade e se manter a duras penas. Mas adverte que eles podem usufruir da universidade de maneira muito mais positiva quando recebem apoio na forma de algumas políticas, como, no caso da USP, o oferecimento de moradia estudantil, bolsa-alimentação ou refeições a preços subsidiados ${ }^{6}$ etc. Certa vez, ouvi de um professor da Faculdade de Educação ${ }^{7}$ a seguinte aposta: "Tenho certeza que o índice de ingresso de alunos de escolas públicas na USP, assim como na Unesp e Unicamp, aumentaria com uma política simples: isenção de taxas de inscrição no vestibular a todas as escolas públicas do Estado de São Paulo". Compartilho da opinião e me parece que o trabalho de Almeida leva a pensar o modo pelo qual os alunos de escolas públicas - mais pobres - são afastados do projeto de concorrer a uma universidade de excelência como a USP e outras públicas, uma vez que se autoexcluem pelas representações sobre as universidades como instituições elitistas, barra-

6. Atualmente, uma refeição no restaurante universitário custa, ao estudante, $\mathrm{R} \$ 1,90$. O preço mantém-se há dez anos.

7. Trata-se do prof. Amaury Cesar de Moraes. dos não pelo vestibular, mas antes até dele. $\bigcirc$ livro leva a olhar, sobretudo, para um segmento importante dos alunos, que poderia usufruir mais das políticas universitárias de permanência se tivesse a orientação adequada por parte da própria universidade, criando condições de formar uma nova e saudável "elite".

Arlene Martinez Ricoldi

Doutoranda em Sociologia pela Universidade de São Paulo aricoldi@uol.com.br

\section{PROFESSORES DO BRASIL: IMPASSES E DESAFIOS}

Bernardete A. Gatti (coord.) e Elba

Siqueira de Sá Barretto

Brasilia: Unesco, 2009, 294 p.

Um estudo abrangente e alentado sobre a formação de professores e o exercício da docência na educação básica é apresentado neste livro, lançado há poucos meses pela Unesco. $\bigcirc$ trabalho oferece um panorama da inserção profissional dos professores no cenário socioeconômico e cultural do país, bem como examina aspectos centrais da sua formação. As autoras recuperam pontos-chave da legislação que rege os modelos de formação docente e analisam os gargalos das licenciaturas presenciais, os desequilíbrios presentes nas grades curriculares dos cursos superiores, agora encarregados de preparar os professores de todas as etapas da educação, e também discutem as características e as divergências relativas às licenciaturas a distância. Informações relevantes acerca do perfil dos universitários que procuram a docência, dos cursos de formação continuada e da carreira docente completam a análise da atual condição dos professores no Brasil.

O primeiro capítulo reúne, com muita propriedade, dados extraídos principalmente da Relação Anual de Informações Sociais Rais -, realizada pelo Ministério do Traba- 
Iho, e da Pesquisa Nacional de Amostra por Domicílio - Pnad -, efetuada pelo Instituto Brasileiro de Geografia e Estatística - IBGE -, aliando essas informações às do Censo Escolar da Educação Básica, feito pelo Ministério da Educação, para apresentar o cenário da profissão docente. Os professores correspondem ao terceiro maior grupo profissional no total de empregos formais no país, sendo que mais de $80 \%$ deles ocupam postos públicos de trabalho. Ou seja, além do seu importante papel cultural, mobilizam uma enorme carga orçamentária do Estado, ângulo de análise que merece ser mais bem explorado pelos estudos da área. $\bigcirc$ texto traça um perfil socioeconômico dos docentes e levanta algumas características do seu trabalho. Ao final reitera a preocupação com a quantidade de professores ainda não formados no ensino superior ou na sua área de atuação e considera a distribuição desigual de oferta pública e privada de vagas nos cursos superiores.

Ao referir-se, no capítulo 2, aos marcos legais dos cursos de formação de professores, o estudo traça o percurso da formação docente desde o curso normal, a habilitação magistério, os Centros Específicos de Formação e Aperfeiçoamento para o Magistério - Cefans -, os Institutos Superiores de Educação até a recente deliberação que atribui, à graduação em Pedagogia, a responsabilidade pela formação de professores para as séries iniciais do ensino fundamental e da educação infantil. As autoras alertam para a complexidade dessa tarefa, que se sobrepõe à formação de especialistas em educação, e para os riscos de simplificações na elaboração de matrizes curriculares que comprometem o preparo específico para a docência nesses cursos.

O terceiro capítulo focaliza a formação inicial para a docência em termos da distribuição da oferta e demanda de vagas no país e conclui que as condições de formação dos professores, de modo geral, ainda estão muito distantes de serem satisfatórias. Mostra que a preparação de docentes para o ensino básico está sendo feita sobretudo pelo setor público nas regiões com economia menos dinâmica. Entre as instituições públicas do país, destacamse as estaduais nessa tarefa.

As licenciaturas a distância são tratadas no capítulo 4, de forma a compor uma visão ampla e crítica sobre um tema emergente e complexo. O texto traz numerosas informações e referências que podem subsidiar outros estudos na área. Nas análises empreendidas, as autoras resgatam iniciativas de sucesso nessa modalidade e também apontam dificuldades, contradições e fragilidades observadas em sua expansão. Valorizam o potencial de democratização do ensino superior por essa via, ao mesmo tempo em que expressam o temor, fundamentando as suas apreensões, de que o ensino a distância possa resultar em formação ainda mais precária que a oferecida pelos cursos presenciais.

No capítulo 5, Gatti e Barretto se reportam a estudo que discute os currículos dos cursos que formam os docentes do ensino fundamental, englobando as licenciaturas em Pedagogia, Letras, Matemática e Ciências Biológicas. A análise destaca a desproporção entre a carga horária das disciplinas referentes à formação profissional específica e das outras disciplinas, em detrimento das primeiras. Registram a preocupação com a falta de articulação entre teoria e prática nos currículos examinados, bem como com a desvalorização das licenciaturas no modelo brasileiro de universidade.

A síntese a respeito de quem são os estudantes universitários das carreiras que conduzem à docência, apresentada no capítulo 6, sistematiza informações coletadas pelo Exame Nacional de Cursos - Enade - em 2005, referentes aos estudantes de Pedagogia e demais licenciaturas. De um modo geral eles conjugam 
trabalho e estudo, e muitos são oriundos de famílias de baixa renda. As informações sobre o sexo dos alunos corroboram outros dados sobre a feminização da carreira docente, notadamente nos cursos de Pedagogia. Chama a atenção o fato de a maior parte dos estudantes não demonstrar grande interesse pela docência; esta aparece como uma segunda opção de atividade profissional.

No capítulo 7, são mencionadas as principais iniciativas de modalidades especiais de formação de professores, voltadas para docentes das redes públicas sem titulação em nível superior. Trata-se de um bom conjunto de referências na área e as autoras destacam como contribuição de alguns desses programas o cuidado com o planejamento do currículo e dos conteúdos, os quais têm como foco as habilidades profissionais básicas para o trabalho na escola e em sala de aula.

O tema da formação continuada é abordado no capítulo 8, em que são citadas experiências bem-sucedidas. Aponta-se para uma reconceitualização da educação continuada, a qual passa a incluir o reconhecimento de uma experiência profissional preexistente que serve de base para o desenvolvimento de novos conceitos e concepções. Alerta-se também para o fato de que a formação continuada acaba, muitas vezes, por funcionar como uma educação compensatória em vista da necessidade de suprir lacunas geradas por dificuldades na formação inicial dos docentes.

As condições profissionais dos professores são contempladas no capítulo I0, no que tange à carreira e ao salário de docentes da educação básica. O rendimento médio dos professores é mais baixo se comparado a outras profissões que exigem nível superior, mesmo diante daquelas consideradas profissões femininas. Há indicações de que ainda são tímidas as iniciativas para a elaboração de planos de carreira docente que contemplem a possibilidade de progredir na carreira sem precisar abandonar a sala de aula. Salário e carreira são, portanto, dois aspectos muito ligados ao futuro do ensino no país e ao interesse manifesto pelas novas gerações para ingressar na docência.

Por fim, Gatti e Barretto, ao considerarem a complexidade dos temas educacionais e os muitos desafios para superar os problemas detectados, ressaltam a necessidade de ultrapassar interesses político-partidaristas e de adotar estratégias articuladas entre as diferentes instâncias formadoras de professores e as que os contratam como profissionais, com o fito de buscar soluções que tornem possível a melhoria da qualidade da educação oferecida no país.

Marina Muniz Rossa Nunes

Pesquisadora do Departamento de Pesquisas Educacionais da Fundação Carlos Chagas mnunes@fcc.org.br 